\title{
Triple-negative breast cancer: New therapeutic options via signalling transduction cascades
}

\author{
ULRICH ANDERGASSEN, ALEXANDRA C. KÖLBL, JAN-NICLAS MUMM, \\ SVEN MAHNER and UDO JESCHKE
}

\begin{abstract}
Department of Obstetrics and Gynaecology, Ludwig-Maximilians University of Munich, 80337 Munich, Germany
\end{abstract}
Received December 8, 2016; Accepted March 3, 2017

DOI: $10.3892 /$ or.2017.5512

\begin{abstract}
Triple-negative breast cancer is a highly aggressive type of mammalian carcinoma. It is defined by a rather weak expression of estrogen-, progesterone- and Her2-receptor, and is thus difficult to treat, resulting in low disease-free and overall survival rates of the affected patients. Hence it is important to find new therapeutic options. To this aim we analysed the incidence of some molecules from different signal transduction cascades by immunohistochemistry, which are known to correlate with triple-negative breast cancer, and correlated the expression of these molecules to different tumour traits, such as size, grading, menopausal stage, histology, lymph node affection, remote metastasis formation, and to the incidence of local and lymph node recurrence and metastasis by statistical analysis. Statistically significant correlations were found for a number of tumour characteristics and signalling molecules: HIF1 $\alpha$ is correlated to tumour grading, $\beta$-catenin to the menopausal state of the patient, and for Notch1 a relation to lymph node affection is seen. In terms of different recurrences, a correlation of
\end{abstract}

Correspondence to: Dr Udo Jeschke, Department of Obstetrics and Gynaecology, Ludwig-Maximilians University of Munich, Maistrasse 11, 80337 Munich, Germany

E-mail: udo.jeschke@med.uni-muenchen.de

Abbreviations: CSCs, cancer stem cells; DFS, disease-free survival; ECM, extracellular matrix; EGFR, endothelial growth factor receptor; EMT, epithelial to mesenchymal transition; ER, estrogen receptor; FOXP3, forkhead box protein 3; Her2, human epidermal growth factor receptor 2 ; HIF1 $\alpha$, hypoxia inducible factor $1 \alpha$; IRS, immunreactive score; LRP6, low-density lipoprotein receptor-related protein 6; MCL1, myeloid leukemia cell differentiation protein 1; MMP13, matrix metalloprotease 13; OAS, overall survival; PARP, poly(ADP-ribose) polymerase; PR, progesterone receptor; TNBC, triple-negative breast cancer; VEGF, vascular endothelial growth factor; XBP1, X-box binding protein 1

Key words: triple-negative breast cancer, signal transduction cascades, cancer treatment, immunohistochemistry, statistical analysis, tumour traits, recurrence $\beta$-catenin to metastasis formation and lymph node affection could be shown, as well as coherences between XBP1 and lymph node recurrence, Notch1 and metastasis formation and FOXP3 and the occurrence of local recurrence. The presented results are in accordance with formerly published studies and therefore might comprise opportunities to develop new therapeutical strategies, which could help to handle this aggressive form of breast cancer in a manner, by which side effects would be reduced and therapeutical efficiency is increased.

\section{Introduction}

Breast Cancer is still the most frequent malignant disease worldwide, and the most frequent cause of death in women (1). One out of eight women is diagnosed with breast cancer during her lifetime. Although lethality has declined in the last 40 years, still $30 \%$ of the affected patients die from the consequences of breast cancer (2).

Approximately $10-20 \%$ of all diagnosed breast cancers are characterized by a lack of expression or a only very weak expression of the hormone receptors, estrogen- and progesterone-receptor, and of the human epidermal growth factor receptor 2 (Her2) (3). These quite aggressive tumours, which are termed 'triple-negative breast cancer' [TNBC (4)], occur frequently in younger women, many of them show up with BRCA-1 mutations (5). Patients suffering from TNBC may develop visceral metastases, have a high risk of recurrence and a reduced overall survival (6), independent of tumour size, staging and lymph node affection (7).

Furthermore, the possibilities for treatment are sparse, as endocrine therapy with Tamoxifen or aromatase-inhibitors as well as anti-Her2 therapy with Trastuzumab are ineffective. Actually, TNBCs are treated postoperatively with a dose-dense or metronome chemotherapy using anthracyclins or taxans and radiation (8). Only in the neoadjuvant setting TNBC shows a better follow-up as non-TNBC (9). Recent therapeutic concepts introduced for example inhibitors of poly(ADPribose) polymerase (PARP) in addition to chemotherapy, such as Iniparib or Olaparib, which are normally responsible for the repair of single- and double-strand DNA breaks. The aim is, to accumulate severe DNA-damage within the tumour cells, that the cells stop entering mitosis, thereby stopping cell division. Thus disease-free survival can be prolonged (10). The risk of recurrence can be reduced by the additional application 
of VEGF inhibitors such as bevacizumab, which decelerates tumour growth by reduction of neoangiogenesis (11). However, the disadvantage of this treatment is, that bevacizumab has rather strong side effects $(12,13)$.

From all those facts the importance of new treatment options can be explained. New therapeutic strategies could target for example inter- and intracellular signal transduction pathways, regulation of cell adhesion and proliferation. Clinical studies are carried out using cetuximab, an inhibitor of epithelial growth factor receptor (EGFR) $(14,15)$ which seems to improve survival rates without further tumour progression (16), or the mTOR-inhibitor everolimus (17). Another treatment strategy could target the Notch1 pathway. Notch1 plays an important role in normal breast development and cell fate determination. In breast cancer tissue, especially TNBC, this pathway is activated in an aberrant manner. Additionally it has been shown, that an inhibition of Notch signalling by gamma-secretase inhibitors (GSIs) results in antitumour activity by cell cycle arrest, apoptosis and disruption of angiogenesis $(18,19)$.

Notch-pathway members are moreover regulated by HIF1 $\alpha$, which thereby constitutes another possibility for TNBC treatment. Overexpression of the transcription factor HIF1 $\alpha$ is associated with a poor prognosis for the affected patients, and in a mouse model it was shown, that it is important for promoting carcinoma onset and formation of lung metastasis. The deletion of HIF $1 \alpha$ resulted in reduced primary tumour growth, suppression of lung metastasis and prolonged survival (20). HIF1 $\alpha$ and XBP1 in turn form a transcriptional complex, which is known to drive tumorigenicity. XBP1 thereby regulates the expression of HIF1 $\alpha$ targets via recruitment of polymerase II. Hence, XBP1 also plays a role in tumour progression, especially in TNBC, contributing to a poor prognosis. In a cell culture model it was shown, that an inhibition of XBP1 results in a retardation of tumour growth, giving hints to another therapeutic target (21).

Another transcription factor, which is highly expressed in tumour cells is FOXP3, a potent repressor of several oncogenes. Its involves in TNBC susceptibility and prognosis (22), but the prognosis is dependent on the cellular localisation of FOXP3: If it is located in the cytoplasm, it is a marker for poor OAS, but if it remains in the nucleus, OAS is markedly improved (23). Furthermore the Wnt/ $\beta$-catenin signalling pathway could be used for therapeutical intervention, as this pathway regulates the cell cycle, cell growth and tumour progression and is responsible for poor clinical outcomes.

The Wnt/ $\beta$-catenin pathway was shown to be activated in TNBC, the inhibition of Wnt-receptors by, e.g. salinomycin, is already known as therapeutic target, as it induces LRP6 degradation (24). LRP6 in turn, is frequently produced in response to obesity stimuli and induces cell proliferation by interaction with $\mathrm{Ki} 67$ and reduces efficiency of treatment. LRP6 is of great use in TNBC-therapy, as it has no relation with ER, PR, and Her2. Its use as drug target receptor significantly prolonged survival time in a mouse model (25). Another signalling molecule within the Wnt-signal transduction pathway, which might be of therapeutic significance, is MCL1, which modulates mitochondrial physiology, and is associated with enhanced metastasis formation and decreased DFS (26).
Table I. Patient/tumour characteristics.

\begin{tabular}{lc}
\hline Characteristics & No. of patients \\
\hline Tumour size & \\
pT1 & 19 \\
pT2 & 8 \\
pT3 & 1 \\
pT4 & 2 \\
pTx & 1 \\
Lymph node affection & \\
pN0 & 17 \\
pN1 & 11 \\
pN2 & 2 \\
pNx & 1 \\
Metastatic stage & \\
pM0 & 20 \\
pM1 & 1 \\
pMx & 10 \\
Grading & \\
G1 & \\
G2 & 18 \\
G3 & \\
Gx & 1 \\
Histology & 7 \\
Ductal & \\
Lobular & \\
Medullar & \\
Other & \\
\hline & \\
&
\end{tabular}

\section{Materials and methods}

Patient samples. Tumour tissue of breast cancer patients, who underwent breast cancer surgery between 2001 and 2002 were collected by the Department of Obstetrics and Gynaecology of Ludwig-Maximilians University of Munich, and subsequently embedded in paraffin. Ethics approval compliant to the Declaration of Helsinki for the collection of these samples was available (LMU 048-08 and 148-12). Hormone receptor and Her2 status were determined pathologically. Thirty-one patients had a triple-negative receptor state and were studied by immunhistochemical analysis. At the time of surgery, patients had an average age of 62 years. Further tumour characteristics are listed in Table I.

Immunohistochemical staining. The paraffin-embedded tissues samples were cut in thin sections by a sliding microtome and transferred onto specially covered microscope slides (SuperFrost Plus, Menzel GmbH, J1800AMNZ/ground $90^{\circ}$ ). The slides were air-dried overnight at $56-58^{\circ} \mathrm{C}$. For the staining procedure paraffin was removed by incubation of the slides in xylol (Merck, 81500) for $20 \mathrm{~min}$, followed by washes in different dilutions of ethanol $(100,90,75 \%)$. Slides were then incubated in $3 \% \mathrm{H}_{2} \mathrm{O}_{2}$ (VWR International, 
Table II. Primary antibodies used for staining.

\begin{tabular}{lllll}
\hline Antibody & \multicolumn{1}{c}{ Clonality } & Working dilution & \multicolumn{1}{c}{ Distributor } & Order no. \\
\hline Anti-HIF1 $\alpha$ & Monoclonal Rabbit-IgG & $1: 2000$ & Sigma Aldrich & HPA001275 \\
Anti-ß-catenin & Polyclonal Rabbit-IgG & $1: 300$ & Diagnostic Biosystems & RP080 \\
Anti-XBP1 & Monoclonal Rabbit-IgG & $1: 400$ & Sigma Aldrich & HPA044305 \\
Anti-FOXP3 & Monoclonal Mouse IgG1 & $1: 300$ & Abcam & ab20034 \\
Anti-NOTCH1 & Monoclonal Mouse-IgG & $1: 100$ & Sigma Aldrich & N5163 \\
Anti-MCL1 & Monoclonal Rabbit-IgG & $1: 1000$ & Abcam & ab53709 \\
Anti-LRP6 & Rabbit-IgG & $1: 80$ & Millipore & $06-017$ \\
\hline
\end{tabular}

ACRO42600100) to reduce activity of endogenous peroxidase and thereby to prevent unspecific staining of tissue samples. Following slides were again washed in ethanol and water and boiled in Na-Citrate (Merck, 106448) Buffer (pH 6.00) for $5 \mathrm{~min}$ to reconstitute the antigens. After cooling down, samples were again washed in water and PBS (Biochrom, order no. L1835). To prevent unspecific binding of the primary antibody, samples are blocked in $10 \%$ normal goat serum (Vector Laboratories, S-1012) for $20 \mathrm{~min}$, then the blocking solution was removed and primary antibodies were applied in the appropriate concentrations (see Table II).

Incubation of primary antibodies was carried out at $4^{\circ} \mathrm{C}$ for $18 \mathrm{~h}$, following slides were washed twice with PBS and incubated with the biotinylated secondary antibody for $30 \mathrm{~min}$ at room temperature. When the secondary antibody was removed, the samples were treated with ABC-reagent (Vector Laboratories, order no. AK-5200) for $30 \mathrm{~min}$, then DAB-reagent (Dako, K-3468), diluted in $\mathrm{H}_{2} \mathrm{O}_{2}$ was added to the slides for $1 \mathrm{~min}$. Enzyme reaction was stopped by washing the slides in water. Nuclei were then counterstained by Hemalaun (Applichem, A0884) for $5 \mathrm{~min}$ before slides are again dehydrated with ethanol and xylol and embedded in Eukitt (Sigma, 03989).

To be sure of the function of the primary antibody, and also to determine its optimal working dilution, a tissue sample, which was confirmed to express the complimentary antigen was stained (tissues used for the antibodies and used concentrations are also given in Table II). Furthermore an isotype control was carried out, staining the same tissue as for the positive control, replacing the primary antibody by a control serum. Thereby the unspecific background of each antibody could be determined.

Microscopy. Staining of the samples was observed and evaluated by two independent persons by a Leitz Diaplan light microscope (Ernst Leitz GmbH, Wetzlar, Germany), equipped with four objectives for different magnifications (x6.3, x10, $\mathrm{x} 25, \mathrm{x} 40$ ). Evaluation was carried out following the immunoreactive score [IRS (27)]. In brief, staining intensity is rated in groups from 0 (no staining) to 3 (strong colour reaction), and number of stained cells is also classified in groups from 0 (no stained cells) to 4 (81-100\% of cells stained). A multiplication of both values results in the IRS score, ranging from 0 to 12 . The IRS is then set into reference with different tumour characteristics.
Statistical evaluation. Statistical analysis was performed by SPSS (SPSS Inc., Chicago, IL, USA) version 22.0. Correlations were calculated by the non-parametric Kruskal-Wallis test. A p-value of $\leq 0.05$ was regarded to be statistically significant.

\section{Results}

Correlation of staining with different tumour characteristics. The TNBC-tissue sections were prepared and stained immunohistochemically (Fig. 1) as described above and an IR-Score was calculated. The IRS was then set into correlation with different tumour characteristics using SPSS software for calculation (Table III). The non-parametric Kruskal-Wallis test revealed a statistically significant correlation of cytoplasmic HIF1 $\alpha$-staining and tumour grading $(\mathrm{p}=0.030)$. A borderline significance was seen for the cytoplasmic staining of $\beta$-catenin and menopausal state $(\mathrm{p}=0.068)$. Furthermore, an association of Notch1 staining, cytoplasmic and nuclear, and lymph node affect on tumours were detected $(p=0.049$ and $\mathrm{p}=0.063$, respectively). For the other tumour parameters such as tumour size, metastatic affection and histological classification no significant correlations could be found. In addition, the other signal molecules investigated in our study, such as nuclear HIF1 $\alpha$, and nuclear $\beta$-catenin, XBP1, MCL1, LRP6 and FOXP3 did not seem to have an influence on tumour characteristics.

Correlation of staining with recurrence. In the following we investigated, if the signal transduction molecules could be correlated to different types of recurrence, such as local recurrence, lymph node recurrence or metastatic recurrence (Table IV). Two statistically strong correlations were seen for $\beta$-catenin: the cytoplasmic staining correlated with the occurrence of remote metastases $(p=0.007)$, whereas the nuclear staining was associated with a lymph node recurrence $(\mathrm{p}=0.018)$. The nuclear $\beta$-catenin staining was also correlated in a borderline manner to the appearance of remote metastasis $(p=0.100)$. Significance of the three more borderline values were found: XBP-1 could be linked to a lymph node recurrence $(\mathrm{p}=0.059)$, nuclear Notch1-staining was connected to remote metastasis formation $(\mathrm{p}=0.082)$ and nuclear FOXP3 seemed to be related to the appearance of local recurrence $(\mathrm{p}=0.083)$. No statistically significant correlations could be found for HIF1 $\alpha$, cytoplasmic Notch1 and FOXP3, Mcl1 and LRP6. 


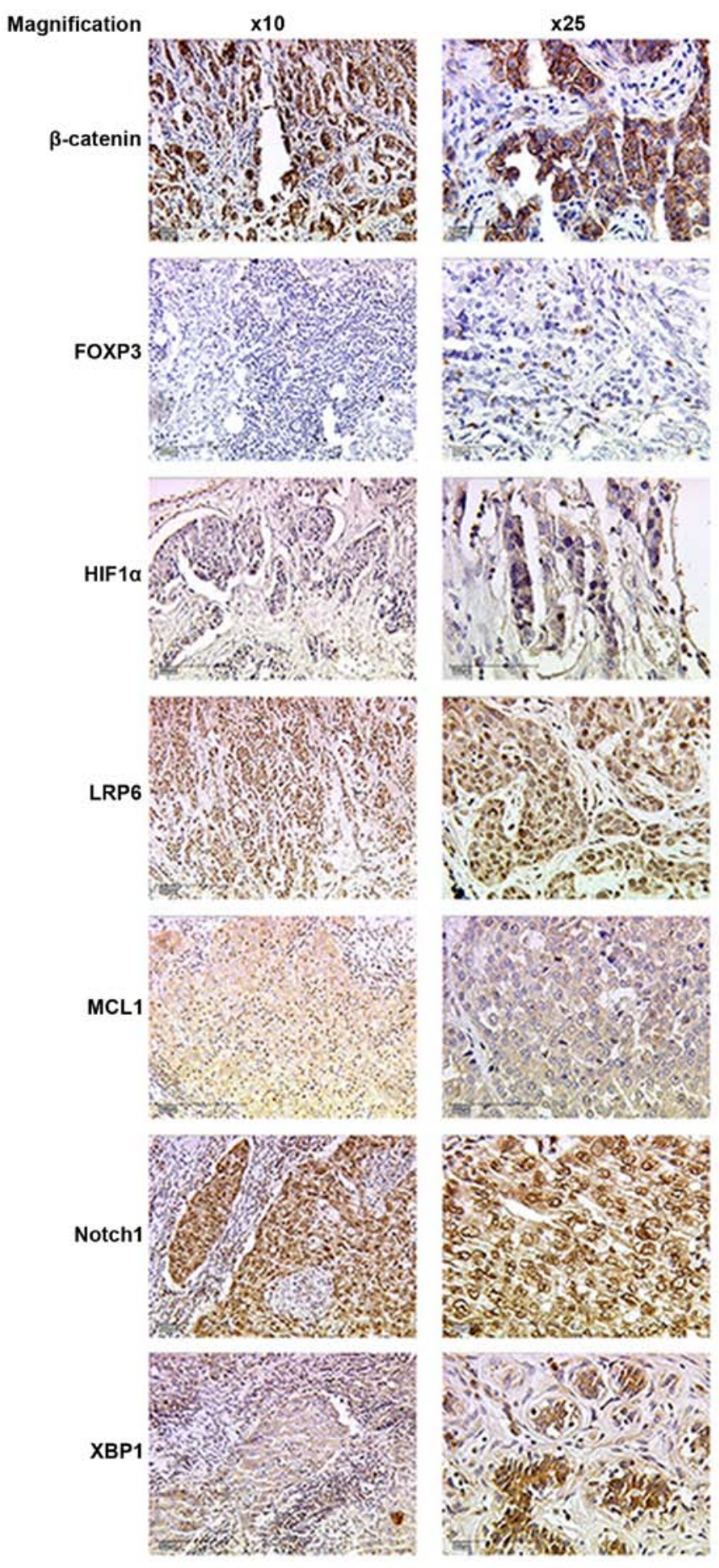

Figure 1. Staining of triple-negative breast cancer tissue with antibodies against the different signal transduction molecules. Images were taken with differen objectives $(\mathrm{x} 10, \mathrm{x} 25)$ resulting in different magnifications of tissue structures. Brown, DAB-staining; blue, Hemalaun counterstaining of the nuclei.

\section{Discussion}

The results clearly indicate that some of the analysed signal transduction molecules have a correlation to the incidence of patient and tumour traits, and are furthermore correlated to different recurrences. The novelty of this study lies in the combination of marker molecules of breast cancer tissue samples and their correlation to other tumour and patient characteristics, especially of the rather aggressive and hard to treat triple-negative breast cancer subtype.
A drawback of the presented study is of course the small number of patient samples analysed, so that the results have to be considered as preliminary. However, the data already show up a certain trend, which should be clarified by the analysis of a larger patient collective. A higher number of samples analysed would also improve the statistical significance.

Nevertheless, some of these findings are in accordance to recently published data, either in breast cancer or in other tumour entities. The correlation of HIF1 $\alpha$ to the histological grading was already described for ovarian cancer (28), where this factor might become important for prognostic evaluation and clinical treatment. Moreover, the linkage between $\beta$-catenin and menopausal stage might be of clinical relevance, as Wang et al found, that the Wnt-pathway influenced the pathogenesis of postmenopausal osteoporosis (29). The Wnt/ $\beta$ catenin pathway also contributes to radioresistence of TNBC cells. Niclosamide, a potent inhibitor of the Wnt/ $\beta$-catenin pathway might be able to abolish the radioresistence of these cells, improving the TNBC-therapy (30).

Wnt/ $\beta$-catenin and Notch1 are normally responsible for mammary gland morphogenesis during embryonal development and are frequently found to be upregulated during tumorigenesis, creating another treatment option (31). The role of Notch1 in lymph node affected infiltrating ductal carcinomas was already described in the literature, claiming the involvement of Notch1 in epithelial-mesenchymal transition (32) which is a rather important process in metastasis formation. Furthermore patients with high expression of Notch1 had a worse OAS and DFS (33). Recently, the microRNA, miR9, was identified to regulate Notch1 in a manner to suppress its tumorigenic capacity (34). Furthermore, the ATPase, a2V-ATPase, was identified, which is necessary for the processing of Notch1-receptor. A deficiency of this ATPase was shown to disrupt Notch signalling and mammary gland development, which might also represent a new way in breast cancer treatment (35).

However, we did not find correlations of tumour characteristics with XBP1, MCL1, LRP6 and FOXP3, and no relation could be shown between tumour size, remote metastasis formation and tumour histology and one of the investigated signalling molecules.

Additionally we investigated the coherence between the different signalling molecules and the formation of recurrence such as lymph node recurrence, local recurrence or remote metastasis formation. We found a correlation between the expression of $\beta$-catenin and the incidence of remote metastasis. It was published earlier, that $\beta$-catenin plays a role in metastasis formation by interactions with ECM (extracellular matrix) 1 protein, what increased the progress on EMT and CSC (cancer stem cell) phenotype maintenance in the cancer cells (36). Furthermore, $\beta$-catenin is known to support the action of matrix-metalloproteinases (MMPs) and uPA (urokinase plasminogen activator), its inhibition thereby inhibits EMT (37). The inhibition of $\beta$-catenin seems to correlate with the inhibition of metastasis formation $(38,39)$. However, $\beta$-catenin also plays a role in lymph node recurrence formation (40), as we also demonstrated with our experiments. An association of Notch1 and remote metastasis formation, which we found in our analysis, was also already described (41) and seems to work via angiogenesis. 
Table III. Statistical correlation of stainings with tumour characteristics (Kruskal-Wallis test).

\begin{tabular}{|c|c|c|c|c|c|c|c|c|c|c|c|c|}
\hline \multirow{2}{*}{$\begin{array}{l}\text { Tumour } \\
\text { trait }\end{array}$} & \multicolumn{2}{|c|}{ HIF $1 \alpha$} & \multicolumn{2}{|c|}{$\beta$-catenin } & \multirow{2}{*}{ XBPI } & \multicolumn{2}{|c|}{ Notch1 } & \multicolumn{2}{|c|}{ Mcl1 } & \multirow{2}{*}{ LRP6 } & \multicolumn{2}{|c|}{ FoxP3 } \\
\hline & Cytoplasm & Nucleus & Cytoplasm & Nucleus & & Cytoplasm & Nucleus & Cytoplasm & Nucleus & & Cytoplasm & Nucleus \\
\hline Grading & 0.030 & 0.269 & 0.980 & 0.516 & 0.225 & 0.530 & 0.537 & 0.302 & 0.279 & 0.443 & 0.711 & 0.445 \\
\hline Size & 0.849 & 0.331 & 0.384 & 0.701 & 0.154 & 0.112 & 0.369 & 0.672 & 0.705 & 0.355 & 0.282 & 0.369 \\
\hline $\begin{array}{l}\text { Lymph node } \\
\text { affection }\end{array}$ & 0.208 & 0.751 & 0.377 & 0.656 & 0.615 & 0.049 & 0.063 & 0.605 & 0.233 & 0.154 & 0.189 & 0.707 \\
\hline Metastases & 0.704 & 0.982 & 0.189 & 0.659 & 0.921 & 0.294 & 0.706 & 0.769 & 0.938 & 0.458 & 0.667 & 0.627 \\
\hline Histology & 0.594 & 0.317 & 0.192 & 0.426 & 0.984 & 0.350 & 0.315 & 0.426 & 0.556 & 0.315 & 0.755 & 0.392 \\
\hline $\begin{array}{l}\text { Menopausal } \\
\text { state }\end{array}$ & 0.750 & 0.591 & 0.068 & 0.609 & 0.767 & 0.476 & 0.298 & 0.557 & 0.151 & 0.802 & 0.663 & 0.542 \\
\hline
\end{tabular}

Bold, statistically significant $\mathrm{p}$-values ( $\mathrm{p} \leq 0.05)$; italics, borderline significant values $(\geq 0.1-\mathrm{p} \leq 0.05)$.

Table IV. Statistical correlation of stainings with tumour recurrence (Kruskal-Wallis test).

\begin{tabular}{|c|c|c|c|c|c|c|c|c|c|c|c|c|}
\hline \multirow{2}{*}{$\begin{array}{l}\text { Type of } \\
\text { recurrence }\end{array}$} & \multicolumn{2}{|c|}{ HIF1 $\alpha$} & \multicolumn{2}{|c|}{$\beta$-catenin } & \multirow{2}{*}{ XBPI } & \multicolumn{2}{|c|}{ Notch1 } & \multicolumn{2}{|c|}{ Mcl1 } & \multirow{2}{*}{ LRP6 } & \multicolumn{2}{|c|}{ FoxP3 } \\
\hline & Cytoplasm & Nucleus & Cytoplasm & Nucleus & & Cytoplasm & Nucleus & Cytoplasm & Nucleus & & Cytoplasm & Nucleus \\
\hline Local & 0.188 & 0.787 & 0.946 & 0.209 & 0.909 & 0.188 & 0.163 & 0.621 & 0.112 & 0.270 & 0.448 & 0.083 \\
\hline Lymph node & 0.312 & 0.953 & 0.239 & 0.018 & 0.059 & 0.312 & 0.418 & 0.638 & 0.241 & 0.470 & 0.508 & 0.906 \\
\hline Metastatic & 0.896 & 0.965 & 0.007 & 0.100 & 0.225 & 0.370 & 0.082 & 0.387 & 0.560 & 0.426 & 0.661 & 0.761 \\
\hline
\end{tabular}

Bold, statistical significant $p$-values $(p \leq 0.05)$; italics, borderline significant values $(\geq 0.1-p \leq 0.05)$

Rather new are the coherence of XBP1 and lymph node recurrences and FOXP3 and local recurrences, showing ultimately, that all these signal transduction pathways are rather important in tumorigenicity and recurrence formation.

As a conclusion of the experiments, the correlation of staining of different signal transduction molecules to tumour traits, indicated that signal transduction pathways influence tumour progression and recurrence or metastasis formation. As the number of samples used in the study is rather small, the results have to be considered as preliminary and further research has to be done to verify these data. Carrying out such experiments could help to refine prognosis and find ways to inhibit tumour progression and metastasis formation and thereby might help to find new therapeutic strategies.

\section{References}

1. Robert Koch Institut: Krebs in Deutschland 2011/2012. 10th edition. Berlin, 2015 (In German). http://www.gekid.de/ Doc/krebs_in_deutschland_2015.pdf

2. National Cancer Institute: www.cancer.govNIH. Accessed Nov 2015.

3. Badve S, Dabbs DJ, Schnitt SJ, Baehner FL, Decker T, Eusebi V, Fox SB, Ichihara S, Jacquemier J, Lakhani SR, et al: Basal-like and triple-negative breast cancers: A critical review with an emphasis on the implications for pathologists and oncologists. Mod Pathol 24: 157-167, 2011.

4. Brenton JD, Carey LA, Ahmed AA and Caldas C: Molecular classification and molecular forecasting of breast cancer: Ready for clinical application? J Clin Oncol 23: 7350-7360, 2005.
5. Dawood S: Triple-negative breast cancer: Epidemiology and management options. Drugs 70: 2247-2258, 2010.

6. Kennecke H, Yerushalmi R, Woods R, Cheang MC, Voduc D, Speers CH, Nielsen TO and Gelmon K: Metastatic behavior of breast cancer subtypes. J Clin Oncol 28: 3271-3277, 2010.

7. Hugh J, Hanson J, Cheang MC, Nielsen TO, Perou CM, Dumontet C, Reed J, Krajewska M, Treilleux I, Rupin M, et al: Breast cancer subtypes and response to docetaxel in node-positive breast cancer: Use of an immunohistochemical definition in the BCIRG 001 trial. J Clin Oncol 27: 1168-1176, 2009.

8. Mehta RS: Dose-dense and/or metronomic schedules of specific chemotherapies consolidate the chemosensitivity of triplenegative breast cancer: A step toward reversing triple-negative paradox. J Clin Oncol 26: 3286-3288, 2008.

9. Liedtke C, Mazouni C, Hess KR, André F, Tordai A, Mejia JA, Symmans WF, Gonzalez-Angulo AM, Hennessy B, Green M, et al: Response to neoadjuvant therapy and long-term survival in patients with triple-negative breast cancer. J Clin Oncol 26: 1275-1281, 2008

10. O'Shaughnessy J, Osborne C, Pippen JE, Yoffe M, Patt D, Rocha C, Koo IC, Sherman BM and Bradley C: Iniparib plus chemotherapy in metastatic triple-negative breast cancer. $\mathrm{N}$ Engl J Med 364: 205-214, 2011.

11. Linderholm BK, Hellborg H, Johansson U, Elmberger G, Skoog L, Lehtiö J and Lewensohn R: Significantly higher levels of vascular endothelial growth factor (VEGF) and shorter survival times for patients with primary operable triple-negative breast cancer. Ann Oncol 20: 1639-1646, 2009.

12. Schutz FA, Jardim DL, Je Y and Choueiri TK: Haematologic toxicities associated with the addition of bevacizumab in cancer patients. Eur J Cancer 47: 1161-1174, 2011.

13. von Minckwitz G, Eidtmann H, Rezai M, Fasching PA, Tesch H, Eggemann H, Schrader I, Kittel K, Hanusch C, Kreienberg R, et al; German Breast Group; Arbeitsgemeinschaft Gynäkologische Onkologie-Breast Study Groups: Neoadjuvant chemotherapy and bevacizumab for HER2-negative breast cancer. N Engl J Med 366: 299-309, 2012. 
14. Grob TJ, Heilenkötter U, Geist S, Paluchowski P, Wilke C, Jaenicke F, Quaas A, Wilczak W, Choschzick M, Sauter G, et al: Rare oncogenic mutations of predictive markers for targeted therapy in triple-negative breast cancer. Breast Cancer Res Treat 134: 561-567, 2012.

15. Viale G, Rotmensz N, Maisonneuve P, Bottiglieri L, Montagna E, Luini A, Veronesi P, Intra M, Torrisi R, Cardillo A, et al: Invasive ductal carcinoma of the breast with the 'triple-negative' phenotype: Prognostic implications of EGFR immunoreactivity. Breast Cancer Res Treat 116: 317-328, 2009.

16. Baselga J, Stemmer S, Pego A, Chan A, Goeminne JC, Graas MP, Kennedy J, Ciruelos Gil EM, Zubel A, et al: Abstract PD01-01: Cetuximab + cisplatin in estrogen receptor-negative, progesterone receptor-negative, Her2-negative (triple-negative) metastatic breast cancer: Results of the randomized phase II BALI-trial. Cancer Res (Thirty-Third Annual CTRC-AACR San Antonio Breast Cancer Symposium) 70: PD01-01, 2010.

17. Yunokawa M,Koizumi F, Kitamura Y,Katanasaka Y, Okamoto N, Kodaira M, Yonemori K, Shimizu C, Ando M, Masutomi K, et al: Efficacy of everolimus, a novel mTOR inhibitor, against basal-like triple-negative breast cancer cells. Cancer Sci 103: 1665-1671, 2012

18. Qiu M, Peng Q, Jiang I, Carroll C, Han G, Rymer I, Lippincott J, Zachwieja J, Gajiwala K, Kraynov E, et al: Specific inhibition of Notch1 signaling enhances the antitumor efficacy of chemotherapy in triple negative breast cancer through reduction of cancer stem cells. Cancer Lett 328: 261-270, 2013.

19. Zhu H, Bhaijee F, Ishaq N, Pepper DJ, Backus K, Brown AS, Zhou X and Miele L: Correlation of Notch1, pAKT and nuclear $\mathrm{NF}-\mathrm{\kappa B}$ expression in triple negative breast cancer. Am J Cancer Res 3: 230-239, 2013.

20. Schwab LP, Peacock DL, Majumdar D, Ingels JF, Jensen LC, Smith KD, Cushing RC and Seagroves TN: Hypoxia-inducible factor $1 \alpha$ promotes primary tumor growth and tumor-initiating cell activity in breast cancer. Breast Cancer Res 14: R6, 2012.

21. Chen X, Iliopoulos D, Zhang Q, Tang Q, Greenblatt MB Hatziapostolou M, Lim E, Tam WL, Ni M, Chen Y, et al: XBP1 promotes triple-negative breast cancer by controlling the HIF1o pathway. Nature 508: 103-107, 2014

22. Lopes LF, Guembarovski RL, Guembarovski AL, Kishima MO, Campos CZ, Oda JM, Ariza CB, de Oliveira KB, Borelli SD and Watanabe MA: FOXP3 transcription factor: A candidate marker for susceptibility and prognosis in triple negative breast cancer. Biomed Res Int 2014: 341654, 2014.

23. Takenaka M,Seki N, Toh U, Hattori S, Kawahara A, Yamaguchi T, Koura K, Takahashi R, Otsuka H, Takahashi H, et al: FOXP3 expression in tumor cells and tumor-infiltrating lymphocytes is associated with breast cancer prognosis. Mol Clin Oncol 1: 625-632, 2013

24. Kim W, Kim SY, Kim T, Kim M, Bae DJ, Choi HI, Kim IS and Jho E: ADP-ribosylation factors 1 and 6 regulate $W n t / \beta$-catenin signaling via control of LRP6 phosphorylation. Oncogene 32 3390-3396, 2013

25. Mahamodhossen YA, Liu W and Rong-Rong Z: Triple-negative breast cancer: New perspectives for novel therapies. Med Oncol 30: 653, 2013

26. Yang L, Perez AA, Fujie S, Warden C, Li J, Wang Y, Yung B, Chen YR, Liu X, Zhang H, et al: Wnt modulates MCL1 to control cell survival in triple negative breast cancer. BMC Cancer 14: $124,2014$.

27. Remmele W and Stegner HE: Recommendation for uniform definition of an immunoreactive score (IRS) for immunohistochemical estrogen receptor detection (ER-ICA) in breast cancer tissue. Pathologe 8: 138-140, 1987.
28. Jin $\mathrm{Y}$, Wang $\mathrm{H}$, Liang $\mathrm{X}$, Ma $\mathrm{J}$ and Wang $\mathrm{Y}$ : Pathological and prognostic significance of hypoxia-inducible factor $1 \alpha$ expression in epithelial ovarian cancer: A meta-analysis. Tumour Biol 35: 8149-8159, 2014

29. Wang Y, Liu Y, Ma JX, Li BX and Li YK: Effect of the Wnt/LRP5/ $\beta$-catenin signaling pathway on the pathogenesis of postmenopausal osteoporosis. Zhonghua Fu Chan Ke Za Zhi 46: 769-772, 2011 (In Chinese).

30. Yin L, Gao Y, Zhang X, Wang J, Ding D, Zhang Y, Zhang J and Chen H: Niclosamide sensitizes triple-negative breast cancer cells to ionizing radiation in association with the inhibition of Wnt/ $\beta$-catenin signaling. Oncotarget 7: 42126-42138, 2016.

31. Rangel MC, Bertolette D, Castro NP, Klauzinska M, Cuttitta F and Salomon DS: Developmental signaling pathways regulating mammary stem cells and contributing to the etiology of triplenegative breast cancer. Breast Cancer Res Treat 156: 211-226, 2016.

32. Cao YW, Wan GX, Sun JP, Cui XB, Hu JM, Liang WH, Zheng YQ, Li WQ and Li F: Implications of the Notch1-Snail/Slug-epithelial to mesenchymal transition axis for lymph node metastasis in infiltrating ductal carcinoma. Kaohsiung J Med Sci 31: 70-76, 2015.

33. Cao YW, Li WQ, Wan GX, Li YX, Du XM, Li YC and Li F: Correlation and prognostic value of SIRT1 and Notch1 signaling in breast cancer. J Exp Clin Cancer Res 33: 97, 2014

34. Mohammadi-Yeganeh S, Mansouri A and Paryan M: Targeting of miR9/NOTCH1 interaction reduces metastatic behavior in triple-negative breast cancer. Chem Biol Drug Des 86: 1185-1191, 2015.

35. Pamarthy S, Mao L, Katara GK, Fleetwood S, Kulshreshta A, Gilman-Sachs A and Beaman KD: The V-ATPase a2 isoform controls mammary gland development through Notch and TGF- $\beta$ signaling. Cell Death Dis 7: e2443, 2016.

36. Lee KM, Nam K, Oh S, Lim J, Kim RK, Shim D, Choi JH, Lee SJ, Yu JH, Lee JW, et al: ECM1 regulates tumor metastasis and CSC-like property through stabilization of $\beta$-catenin. Oncogene 34: 6055-6065, 2015.

37. Kumar KJ, Vani MG, Chueh PJ, Mau JL and Wang SY: Antrodin $\mathrm{C}$ inhibits epithelial-to-mesenchymal transition and metastasis of breast cancer cells via suppression of $S$ mad $2 / 3$ and $\beta$-catenin signaling pathways. PLoS One 10: e0117111, 2015.

38. Li X, Liang W, Liu J, Lin C, Wu S, Song L and Yuan Z: Transducin ( $\beta$ )-like $1 \mathrm{X}$-linked receptor 1 promotes proliferation and tumorigenicity in human breast cancer via activation of betacatenin signaling. Breast Cancer Res 16: 465, 2014.

39. Wang Y, Bu F, Royer C, Serres S, Larkin JR, Soto MS, Sibson NR, Salter V, Fritzsche F, Turnquist C, et al: ASPP2 controls epithelial plasticity and inhibits metastasis through $\beta$-catenin-dependent regulation of ZEB1. Nat Cell Biol 16: 1092-1104, 2014.

40. Sehgal P, Kumar N, Praveen Kumar VR, Patil S, Bhattacharya A, Vijaya Kumar M, Mukherjee G and Kondaiah P: Regulation of protumorigenic pathways by insulin like growth factor binding protein 2 and its association along with $\beta$-catenin in breast cancer lymph node metastasis. Mol Cancer 12: 63, 2013.

41. Dong Y, Zhang T, Li J, Deng H, Song Y, Zhai D, Peng Y, Lu X, Liu M, Zhao Y, et al: Oridonin inhibits tumor growth and metastasis through anti-angiogenesis by blocking the Notch signaling. PLoS One 9: e113830, 2014 